\title{
Research on Application of Unity3D in Virtual Battlefield Environment
}

\author{
Jian $\mathrm{Wu}^{1, *}$, Yaxiong $\mathrm{Li}^{1}$, Qingguo $\mathrm{Liu}^{1}$, Guohua $\mathrm{Su}^{2}$ and Kaifeng $\mathrm{Liu}^{2}$ \\ ${ }^{1}$ Faculty 906, Rocket Force engineer University, Xi'an, 710025, China; \\ ${ }^{2}$ Equipment Academy of Rocket Force, Beijing, 100094, China \\ ${ }^{*}$ Correspondind author
}

\begin{abstract}
Virtual battle environment is an important visible platform for combat simulation. There-dimensional scene simulation is a basic part of virtual battlefield environment. Researching on application of unity3D in virtual battlefield environment is very meaningful. In the paper, involved subjects of there-dimensional scene simulation system based on Unity3D were discussed. The technical route of there-dimensional scene simulation system was researched. The development and application showed that there-dimensional scene simulation system based on Unity3D was feasible.
\end{abstract}

Keywords-unity3d; virtual reality; battlefield environment; 3dmax modeling

\section{INTRODUCTION}

Virtual battle environment is an important visible platform for combat simulation. Combat simulation is very important for such as combat effectiveness evaluation, attack-defense drill, strategic decisions and tactical decisions and so on. Meanwhile, scene simulation is a basic part of the combat simulation. Especially, there-dimensional scene simulation is more intuitive and application.

At present, there are two patterns to develop theredimensional scene simulation system. The first, scene simulation system is based on underlying graphics API (OpenGL or DirectX 3D). The process of developing system is starting with the bottom functional, then constructing theredimensional combat rendering engine. The advantage of the method is low cost. The disadvantage of the method is lots of manpower and more poor quality than the professional simulation platform. The second, scene simulation system is based on the professional simulation platform. The advantage of the method is more quality. However, the method has poor adaptation and flexibility.

Especially, for small-scale simulation system, the best method to develop scene simulation is seeking a reasonable breakthrough point between two methods. We do not need strong ability and licensing cost if adopting Unity3D as platform for there-dimensional scene simulation system. Meanwhile, Unity3D is a powerful there-dimensional visual function because which is game development software. High quality hardware is not need to use Unity3D. In this paper, framework program of there-dimensional scene simulation system based on Unity3D is researched. Meanwhile, threedimensional reconstruction of an airport was simulated.

\section{THE OVERVIEW OF VIRTUAL BATTLEFIELD ENVIRONMENT AND UNITY3D}

\section{A. The Overview Of Combat Simulation}

At the beginning of the nineties, the United State takes the lead in applying the 3D technology to military field. Mainly used in the following four areas: virtual battlefield environment, simulated training and evaluation on individual soldiers, joint military exercises between multiple arms and train the commander's command ability. With fast developing of 3D virtual simulation technology, soldier can experience different effect of combat after input different disposal scheme for different individuals, just like they participate in the actual action. By using such kind of training, the skill level, quick reaction ability and psychological bearing capacity can be significantly improved ${ }^{[1,2]}$

Military simulation includes weapons technology simulation, weapons system simulation and combat simulation It has important strategic significance and economic benefits for military combat command in practice.

With the rapid development and mature of virtual reality technology, the virtual reality techniques are applied extensively in many fields. At present, virtual reality technology has been applied in Virtual Battlefield, Virtual Battlefield can help training soldiers, can test and evaluate weapon system's capability and campaign project's advantage and disadvantage, Virtual Battlefield's application promote military emulation. There-dimensional scene simulation is a basic part of virtual battlefield environment ${ }^{[3,4,5]}$.

In recent years, the technology about virtual battlefield environment develops quickly. Virtual battlefield environment is applied to military training of ground force, navy, air force special force and joint training abroad. Research on virtual battlefield environment is still in early stages of the country. So, researching on in virtual battlefield environment is very meaningful.

\section{B. The Overview Of Unity3d}

Unity3D developed by Unity Technologies is an integrated design and development tool. There-dimensional video game, architectural visualization and three-dimensional animation easily are created based on Unity3D.An engine about image, voice and physical and a powerful editor were provided by 
Unity3D.Unity3D supports almost all major three-dimensional animation formats. For developers who do not need understand complex technology about low-level can also develop high performance and quality product, there are two advanced computer language C\# and JavaScript can be used to achieve the script function. Unity3D is a cross-platform for threedimensional engine which supporting Windows, Mac, Linux, Web, IOS, Android, Xbox360 and PlayStation. So it's very easily for developers to reuse code across platforms ${ }^{[6,7,8]}$.

\section{The Design of Combat Simulation RoAming SYSTEM BASED ON UNITY3D}

We use other modeling software due to limited model ability of Unity3D. In the paper, 3DMAX was adopted to established models of airport which adhering well to the unity3D and having strong capacity to establish model. The step of establishing there-dimensional scene simulation system includes model database, there-dimensional modeling, assigning material to the surface and outputting result of FBX scheme and so on.

Model database was established by collecting model data of buildings, roads, rivers and others. Material database was established based on model texture make by Photoshop. Terrain was generated by DEM data. The airport model can be established by models, material and terrain. After building airport model, we can make scripts by C\# and JavaScript to implement system functionality ${ }^{[9,10]}$. The technical route of there-dimensional scene simulation system was shown as figure.1.

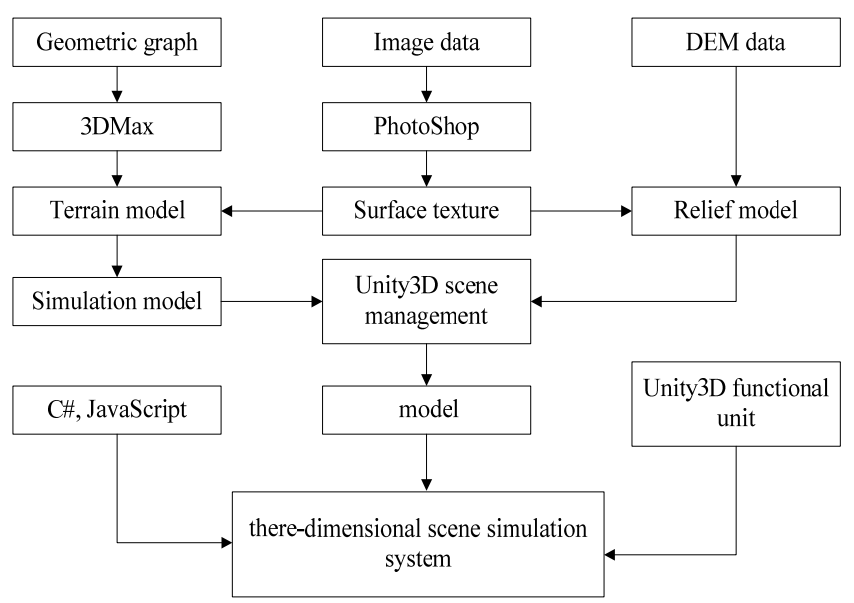

FIGURE I. THE TECHNICAL ROUTE OF THERE-DIMENSIONAL SCENE SIMULATION SYSTEM

\section{A. Data Acquisition}

\section{1) Maps of satellite image}

We can get maps of satellite image by internet. The map of satellite image was base map of airport model. The typical map of satellite image was shown as fig. 2 and fig.3. Meanwhile, we can get point, size and height of buildings.

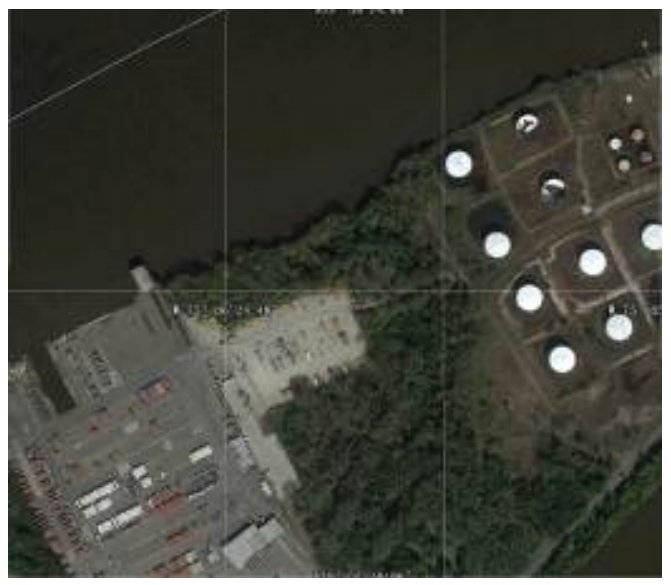

FIGURE II. THE TYPICAL MAP OF SATELLITE IMAGE

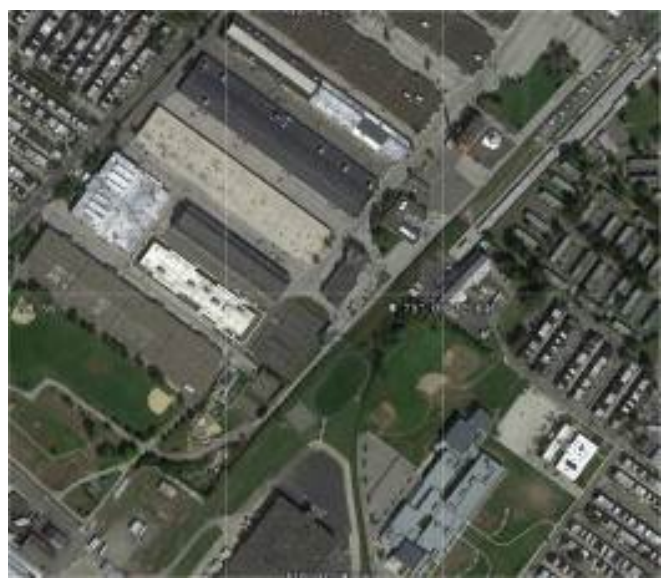

FIGURE III. THE TYPICAL MAP OF SATELLITE IMAGE

The base map of airport model was shown as fig. 4 and figure.5.

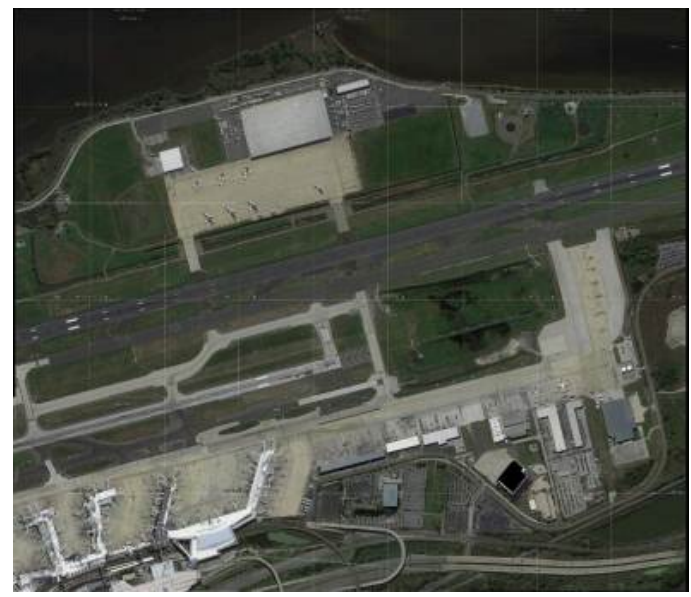

FIGURE IV. THE BASE MAP OF AIRPORT MODEL 


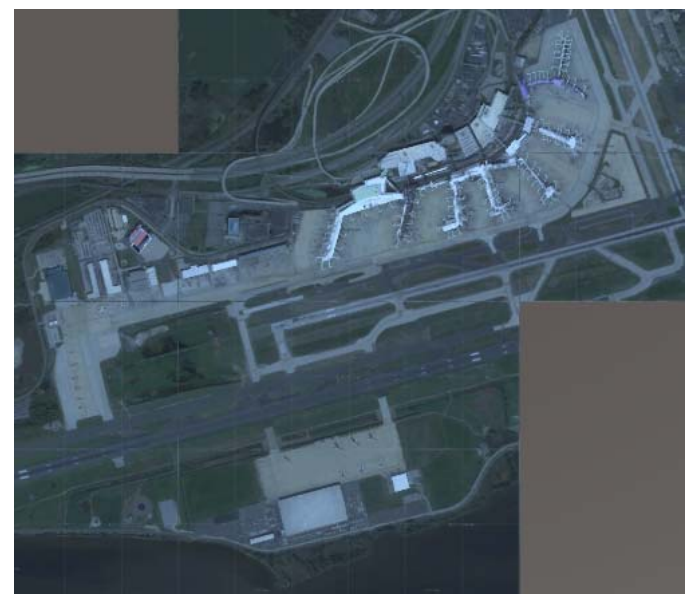

FIGURE V. THE BASE MAP OF AIRPORT MODEL

\section{2) Material textures}

We can get material textures of building by analyzing the satellite image. Material textures were processed by Photoshop. Then material textures were covered model. The typical material textures were shown as figure.6 and figure.7.At last, we get the model of airport by 3DMAX.

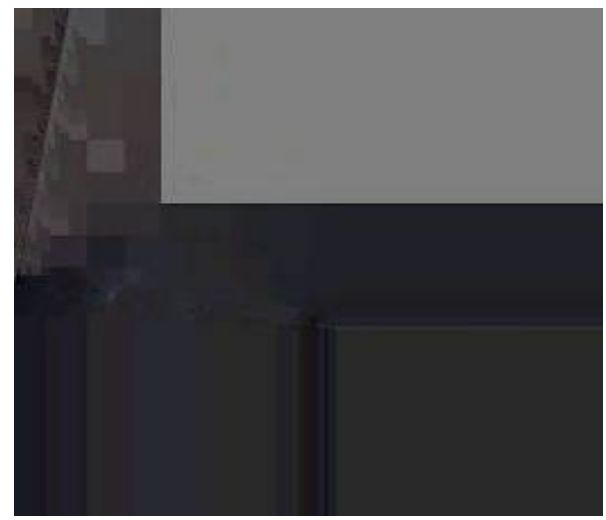

FIGURE VI. THE TYPICAL MATERIAL TEXTURES

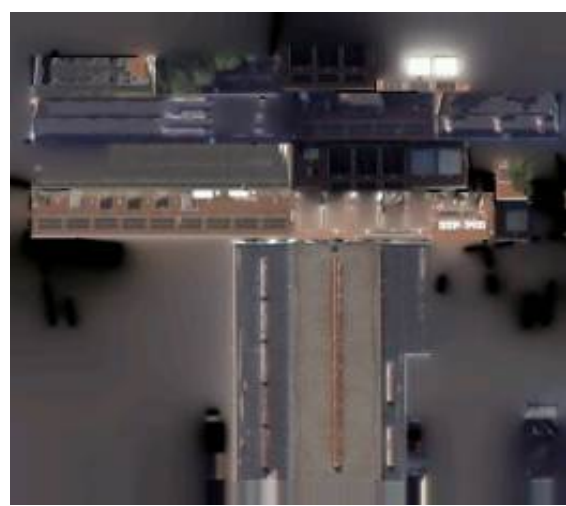

FIGURE VII. THE TYPICAL MATERIAL TEXTURES

\section{B. Modeling}

Generally, the model can divided into foundation model and detailed model in simulation system. Foundation model was tensile as the structure's height according to basic outline of structure. Then a material texture which is equivalent to structures was covered to the model. Foundation model was applied to general building. Detailed model was reconstructed refined based on foundation model which was applied to special target. In the paper, the airport was a detailed model. The typical models were shown as figure.8 and figure.9.

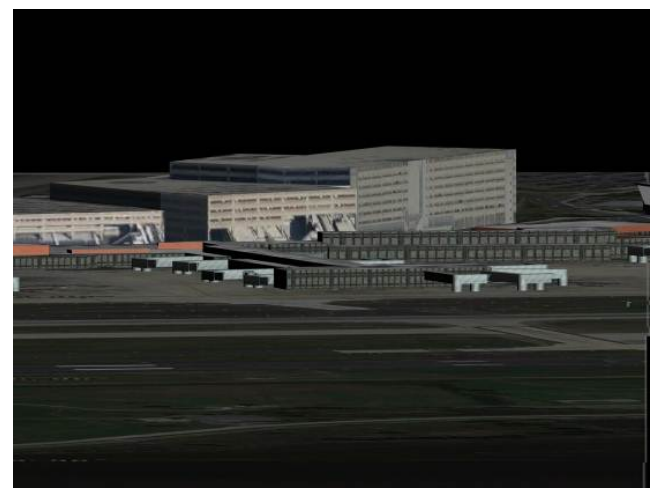

FIGURE VIII. THE TYPICAL MODEL OF AIRPORT

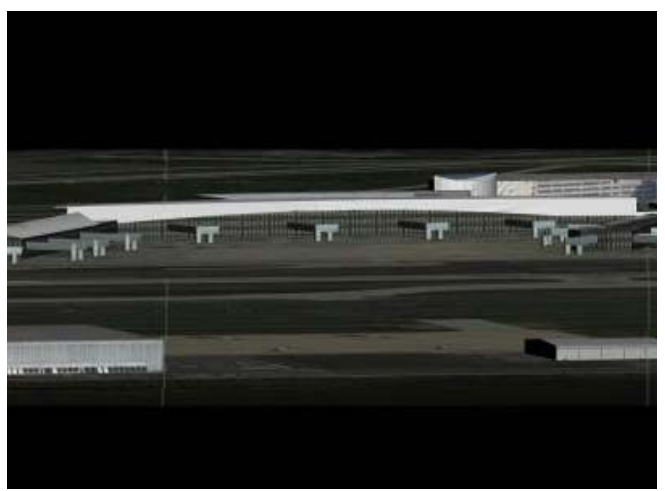

FIGURE IX. THE TYPICAL MODEL OF AIRPORT

\section{Function Implementation}

Based on the model of airport, the script developed by C\# and JavaScript can be implemented function. The skybox was applied to system. The function of there-dimensional scene simulation system includes scene mobile, scene rotation and scene scale.

The simulation result of scene scale was shown fig.10 and fig.11.The simulation result of scene rotation was shown figure.12 and figure.13. 


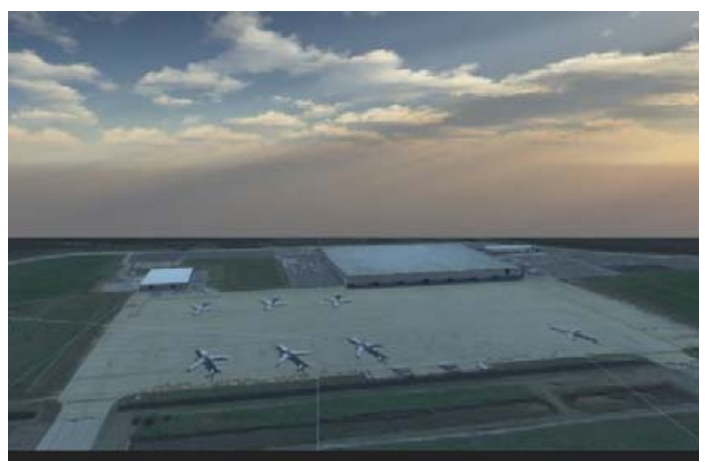

FIGURE X. THE SIMULATION RESULT OF SMALL-SCENE

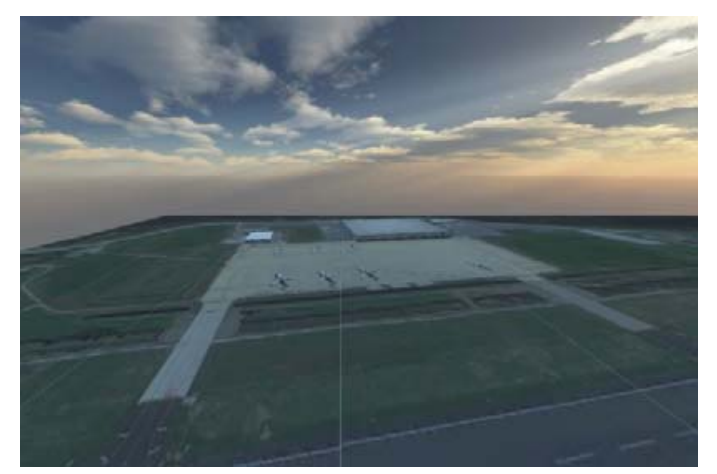

FIGURE XI. THE SIMULATION RESULT OF LARGE-SCENE

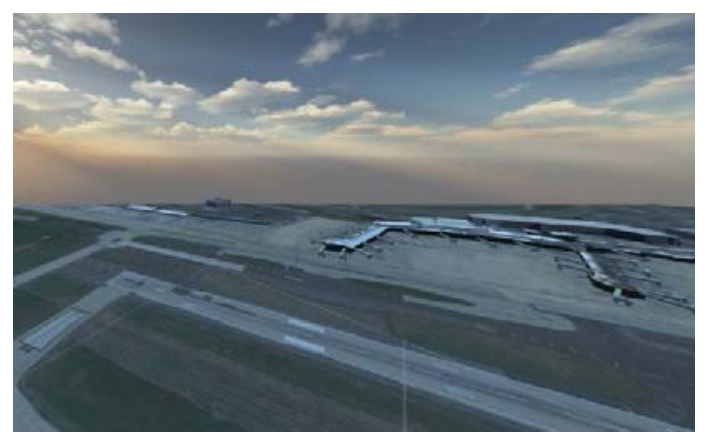

FIGURE XII. THE SIMULATION RESULT OF SCENE

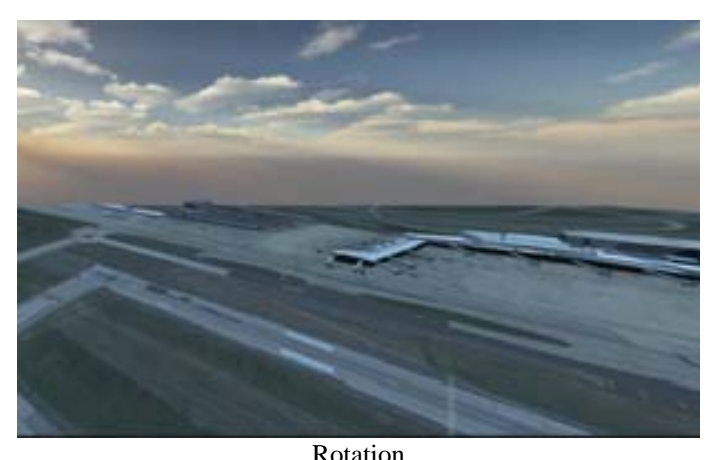

Rotation

FIGURE XIII. THE SIMULATION RESULT OF SCENE ROTATION

\section{CONCLUSION}

The basic models were built by 3DMAX and the material textures were processed by Photoshop in the paper. The model of airport was produced by material textures covered to basic models. After function implementation was simulated by C\# and JavaScript, the there-dimensional scene simulation system was established.

In the paper, involved subjects of there-dimensional scene simulation system based on Unity3D were discussed. The technical route of there-dimensional scene simulation system was researched. The development and application show that there-dimensional scene simulation system based on Unity3D was feasible.

\section{REFERENCES}

[1] Lawrence J. Dacunto. Combat simulations in U.S. Army training and testing, Proceedings of the 1996 Winter Simulation Conference, 896-902, 1996.

[2] ZHU Yan-jun. Research and development of virtual ocean battlefield simulation system based on OpenGL[J].Computer Engineering and Design, 2009,30[J]:1216-1218.

[3] JIANG Xue-zhi, Present situation of researching at home and abroad, Journal of Liaoning Technical University[J],Vo1.23, No.2, 238-240, 2004.

[4] CHEN Shi-hong, WAND Hai. Research and implementation of forest scene walkthrough system[J]. Journal of image and Graphics, 2009,14(6):1212-1216.

[5] LUO Feng, LIU Chu, SUN Ze-chang. Intelligent vehicle simulation and debugging environment based on physics engine[J].IFFF,2009.

[6] REN Jian-bang. Design and implementation of client for phone game based on the Unity3D[D]. Beijing: Beijing Jiaotong University,2013.

[7] LI Jin-yong, WU Yin-sheng, ZHE Jian-feng, ZHAO Ya. The Design and Implementation of Mobile Device Client Based on Unity3D for Oilfield Operation Simulation Examination System, System Simulation Technology[J], Vol.12, No. 1 Feb.,2016

[8] Zhao Yan-kun. The Research of LuanChuan 3D Urban Geographic Information System with Unity3D[D], Zhengzhou University,2014.

[9] WANG Cheng-hao. Research and design of EPOLL based the network game server communication structure[D]. Dalian:Dalian Maritime University,2012.

[10] GAN Chen. Design and Implementation of Virtual Smart Home System Based on the Unity[D], Dalian University of Technology[D],2015. 